\title{
PROGNOSIS IN PAROXYSMAL TACHYCARDIA AND PAROXYSMAL AURICULAR FIBRILLATION
}

\author{
BY \\ W. TREVOR COOKE AND PAUL D. WHITE \\ From the Cardiac Laboratory, Massachusetts General Hospital, Boston, Mass., U.S.A. \\ Received September 12, 1942
}

In 1888, Bristowe wrote of "Recurrent palpitations of extreme rapidity in persons otherwise healthy"; he was, however, extremely guarded as to the correct prognosis in this condition, seeing that six out of nine of the cases he described died before their time. Similarly, two of the three cases recorded by Bouveret (1889) died of congestive failure during an actual paroxysm. Indeed the early reports are characterized by the number of fatal cases, so that it is not surprising to find Herringham (1897) writing " when one sees a robust and healthy person subject to these attacks, it is tempting to make light of them, but this ought never to be done. The condition seems always to tend to get worse and, in the end, to kill."

We do not in our generation take such a gloomy view of the attacks, but even now it is not uncommon to find patients, who are otherwise organically sound, living a life of a cardiac cripple following the pronouncement of a poor prognosis. We are, therefore, submitting our observations on a large number of patients with paroxysmal auricular tachycardia, especially on those who are otherwise perfectly healthy, in order that a more optimistic outlook shall be the rule to counteract the somewhat pessimistic attitude of earlier writers.

The basis of this paper has been chiefly the private case records of one of us (P.D.W.), these consisting of more than 600 cases of paroxysmal tachycardia. In addition, all those in the index files of the Massachusetts General Hospital between the years 1928-38 were reviewed. Numerous others from the cardiographic laboratory were also collected so that the total number of cases considered was more than 750. A separate paper has been submitted dealing with paroxysmal ventricular tachycardia.

\section{Immediate Prognosis of Paroxysmal Auricular Tachycardia}

The likelihood of any particular attack ceasing, in spite of the most alarming symptoms, is practically certain. Cases are, however, encountered from time to time in which death takes place during an attack, and there were seven in this series in which death was due, directly or indirectly, to a paroxysm.

Case 16. A woman, aged 44, was admitted to the hospital on the seventh day of a paroxysm of auricular tachycardia with signs of congestive failure. Shortly after, 
she had a femoral embolus and a little later, during a recurrence of her tachycardia, a cerebral embolus from which she died.

Case 18. A boy, aged 4, had had repeated attacks of tachycardia since the age of 2 , on many occasions developing signs of congestive failure. Injection of the cervical ganglia was carried out with some success, but finally, after numerous and almost continuous paroxysms, he had a cerebral embolus and died.

Case 10. A man, aged 42, started with paroxysms of auricular tachycardia at the age of 16. At 26, he had joint pains and " heart trouble." The attacks of tachycardia became frequent, being associated with loss of consciousness, hæmoptysis, and pulmonary œdema on one or two occasions. Between the attacks he was able to work as a carpenter. He was finally admitted in an attack with acute pulmonary œdema from which he died. He had "tight" mitral stenosis.

Case 29. An obese woman, aged 48, developed paroxysmal auricular tachycardia the morning following bilateral salpingo-oophorectomy and hysterectomy. She became unconscious, with a blood pressure of $80 / 60$, and died 8 hours after the onset. EC., paroxysmal auricular tachycardia, rate 180 .

Case 30. A woman, aged 42 , had had a difficult and prolonged convalescence following an operation for intestinal obstruction. Paroxysmal tachycardia set in 24 hours before death, and did not respond to any treatment. She died after the rapid development of failure (B.P. 60/30). Autopsy showed an apparently normal heart.

Case 31. A woman, aged 57, developed paroxysmal auricular tachycardia, at a rate of 220 , with the picture of profound surgical shock. The temperature gradually rose, and she died in circulatory failure, 12 hours after onset. Her blood pressure was $110 / 80$, her usual pressure being 200/100. Autopsy showed a normal heart.

Case 55. A boy, aged 2, started very frequent paroxysms of auricular tachycardia following pneumonia and whooping cough with the development of congestive failure. No treatment was of any avail and he died.

Very little comment is needed on these cases. Three of the deaths occurred in patients who were already sick from severe major operations. The tachycardia, with the production of profound shock, superimposed upon the trauma of the operation, merely proved to be the straw that broke the camel's back. Two of them, it will be seen, developed cerebral emboli. Just as there is always a possibility of cerebral emboli in auricular fibrillation so too the same possibility is always present in a paroxysm of tachycardia that continues for any length of time, especially when congestive failure develops. Case 10 illustrates the danger that is always present in those who have both mitral stenosis and paroxysmal tachycardia. Five others were encountered with mitral stenosis and severe pulmonary œdema from paroxysmal tachycardia, but without a fatal termination.

\section{The Remote Effect of the Paroxysms}

Numerous individual cases in which attacks have occurred over several years have been reported (e.g. Palmer, 1937; Cowan, 1939). Hume (1930) collected a series of 130 cases in which the average duration was over 30 years, while Campbell and Elliott (1939) reported in their series of 100 cases, a group of 28 with apparently normal hearts whose paroxysms had been occurring for an average of 23 years. There were two deaths during the attacks in this group. There is no reported evidence to suggest that permanent organic heart disease may be produced by such repeated paroxysms. 
In this survey, 80 cases with otherwise normal hearts were followed up. These, except for 4 hospital cases, were patients who had been seen in consultation and had had their paroxysms over a period of ten years at least. Of these 80, 57 were traced either by letter, through their own medical practitioner, or in person.

The average age of the group that has been traced was 58 years and the average length of time since the onset of the attacks was 25 years. The longest duration for any patient was 64 years. His attacks apparently caused no serious inconvenience and he classed them merely as a nuisance.

Case 32. A man aged 72, had had his first attack at the age of 7. Since then he had had 1 to 2 attacks of tachycardia for a year, varying from 6 to 24 hours in duration. When last seen, he had diabetes and mild coronary disease, and had 6 to 8 attacks a year which were well controlled with quinidine. He was still very active.

It was found that five of the patients had died, but there was no evidence to associate the paroxysms with the deaths of any of the first three patients.

Case 37. A woman, aged 52, had had paroxysmal tachycardia for approximately 25 years. She died following an operation for gallstones, but the exact details were unknown.

Case 38. A man, aged 69, had had 6 to 8 attacks a year for 32 years. He died of pneumonia despite a week in an oxygen tent.

Case 39. A woman, aged 75 , had had paroxysmal auricular tachycardia for 15 years. The exact cause of death was not known.

Case 40. A man, aged 55, had had paroxysmal auricular tachycardia for 40 years. Over the last 4 years of his life, he suffered with symptoms of hypertensive coronary heart disease. The paroxysms became very much more frequent and congestive failure was precipitated. He died at home, but the details could not be obtained.

Case 26. A woman, aged 50, had had paroxysmal auricular tachycardia for 18 years. It had been extremely troublesome the whole period, at times causing slight cardiac enlargement. She died following an operation for carcinoma of the breast. Autopsy showed a recent auricular infarct.

Unfortunately no adequate histological studies had been carried out on this case and the heart was not available for re-study. The patient herself had been otherwise healthy and able to carry out her duties as a nurse. One can only speculate as to what modifications there may have been in the blood supply of the S-A and A-V nodes. The abnormalities of rhythm during the paroxysms in this case have been reported by Sprague and White (1925).

Thus, concerning the prognosis in patients with paroxysms occurring over many years, there seems to be no conclusive evidence in this small series to justify any adverse statement and, indeed, medico-actuarial figures suggest that such patients have a slightly better expectation of life than normal.

According to Campbell and Elliot, the prognosis of paroxysmal auricular tachycardia " as regards life is excellent, unless appearing relatively late in life it is the first indication of disease of the coronary arteries or unless before the paroxysms have started there is already serious heart disease. In general, the prognosis depends on the condition of the heart muscle and should be decided 
without reference to the paroxysms." It is not, however, our experience that the prognosis is poor, even coming on late in life, and the following two cases are examples of the relative insignificance of attacks in the majority of such patients.

Case 34. A woman, aged 78, began to have rather frequent attacks at the age of 56. These continued until about three years ago when they practically disappeared. She now writes of her excellent health-no doctors, no medicine, and the ability to undertake five-hour train journeys by herself.

Case 35. A woman, aged 80 , started to have attacks when 56, with occasional paroxysms lasting three to six hours. She now has slight hypertension, but is quite active.

Moreover, a survey of 398 consecutive cases of paroxysmal tachycardia seen in consultation showed that there were 69 with coronary heart disease and/or hypertension, with the onset of the arrhythmia after the age of 40 . Included among these there were 16 patients with coronary thrombosis. Out of 128 patients with otherwise normal hearts in this same series, 57 started their attacks after the age of 40 . Thus, excluding the cases of coronary thrombosis, there were approximately equal numbers with and without organic heart disease starting after the age of 40 . The whole of this group has not been followed up, but a large number of the patients had been re-examined from time to time; most of the remainder were first seen four to five years after the onset of the tachycardia. These patients, therefore, form a group from which it is possible to draw some conclusions as to the prognostic significance of tachycardia arising in the second half of life.

Two patients of this older group with apparently normal hearts died unexpectedly. The first died following an operation for gallstones at the age of 52; and the second, a man, also aged 52, died while swimming, one year after he had been diagnosed as having an irritable normal heart. In neither of these were the exact details as to the mode of death available. Even taking into consideration these two deaths, the impression was left that only in a very few of the cases with apparently normal hearts was paroxysmal auricular tachycardia the first symptom of serious organic heart disease.

In the group that already had coronary disease, the attacks of tachycardia did not appear to make any appreciable difference to the ultimate prognosis.

Master, Dack, and Jaffe (1937) studied the arrhythmias that were found in 300 cases of acute coronary thrombosis and found 9 ( 3 per cent) with paroxysmal auricular tachycardia. Only 2 died (a result of the thrombosis), and it was considered that patients with paroxysmal auricular tachycardia usually survived.

Frequent paroxysms might justify a more serious prognosis in a damaged heart than the organic disease itself warrants. It would be logical to suppose that a severe paroxysm of auricular tachycardia with its attendant low blood pressure might easily precipitate a coronary thrombosis. Indeed, the descriptions in some of the earlier reports (e.g. Bristowe, Bouveret) suggest this possibility. In none of the cases in our series was there any evidence to show that such an event had taken place. However, it might be exceedingly difficult to determine which occurred first, the tachycardia or the thrombosis. 
To sum up, paroxysmal auricular tachycardia arising in later life, may warrant a more serious prognosis in individual and comparatively uncommon cases, but as a general rule, the attacks have little or no influence on the ultimate outcome.

Prognosis as to the frequency of the attacks.-It is difficult to give any forecast as to the possibility of gaining complete freedom from the attacks. Some patients, such as Case 41 , had attacks every two to three weeks and became very disheartened because the attacks showed no improvement and, as the years went by, became very much more frequent: while others, such as Case 42, suddenly had complete remission. This patient had increasingly frequent attacks for five years until the tachycardia became almost constant and signs of congestive failure were present: then following treatment with quinidine, she has been entirely free from attacks for fourteen years.

The patient with the most frequent attacks was Case 43, who stated that he had as many as 10 to 12 attacks in a day and that the attacks had been present for the past 25 years.

The prognosis of any given case is inextricably bound up with treatment. Some patients seem to undergo a spontaneous cure, others react to specific treatment, and a number continue unchecked by any measure whatsoever. It seems impossible to foretell in what way a given case will react. As a rough guide, the patients who are extremely neurotic and have developed a marked degree of neurocirculatory asthenia, have a poor chance of getting rid of the attacks.

Duration of the attacks.-Attacks of long duration have been recorded by many writers (Bouveret; Bristowe; Hamilton and Hurvitz, 1932; Gallavardin; Veil and Froment, 1930; Marvin, 1923). It has also been emphasized frequently that such attacks of long duration are uncommon. One infant, aged 18 months, was seen in whom paroxysmal auricular tachycardia had been present for over twelve months; she was otherwise a perfectly normal and welldeveloped child.

Lewis (1936) states that the attacks in each individual patient are usually of the same duration. We have found, however, that the duration of the attacks is extremely variable. It is, therefore, impossible to give a forecast of the length of any future paroxysm, although one can usually safely say that paroxysms of more than 24 hours in duration are uncommon.

\section{Prognosis in Paroxysmal Auricular Fibrillation}

Parkinson and Campbell (1931), as a result of their review of 200 cases of paroxysmal auricular fibrillation, considered that the prognosis in the immediate attack was excellent as it would seldom last more than two days, and that the ultimate prognosis depended mainly on the condition of the heart muscle independently of the paroxysms; though these increased the risk of fibrillation becoming established, which happened in almost one quarter of all the cases and in a higher proportion of those with rheumatic heart disease or with very frequent paroxysms. They made no actual statement, however, as to the 
prognostic meaning of attacks in a damaged heart, whether such attacks would mean a more serious prognosis than a similar heart without such attacks.

White and Bland (1931) in a report on the prognosis of angina pectoris and of coronary thrombosis, found that the incidence of paroxysmal auricular fibrillation was low in both conditions. In the 500 cases of angina, there were only 11 examples and 4 others in which the attack occurred as a terminal event. In the 200 cases of coronary thrombosis, attacks of fibrillation occurred at the time of the actual thrombosis in 13: of these, 4 died after one month and within one year, and 5 others were still alive after four years. From their experience, fibrillation did not seem to increase the gravity of the prognosis.

Master, Dack, and Jaffe (1937) in their 300 cases of acute coronary thrombosis, found 22 with fibrillation. In half these there had been a previous paroxysm. The average age of the group was 60 and the males predominated in the ratio of 2 to 1 . In 18 there was a history of previous hypertension. 10 cases died, 5 during the period of the arrhythmia. Comparing the mortality of the cases with and without arrhythmia in acute thrombosis, they found a slightly increased mortality in the cases with fibrillation. They concluded that the relatively low incidence of abnormal rhythms was due to the copious blood supply to the A-V node protecting it from serious damage.

We found the incidence of auricular fibrillation in a consecutive series of 1400 cases of angina pectoris and coronary thrombosis to be small, only 4 per cent. Many of these, who had coronary heart disease when first seen, were followed for several years until they finally died in a ripe old age. In none of them could it be said that auricular fibrillation had accelerated death. For example, one patient, a physician, had had attacks every three to six months for the past 28 years and was still active at the age of 83 , though he had also intraventricular block. Another example is Case 47, who was still active though restricted at the age of 73 after attacks over the previous 14 years. One woman, aged 76, who had had attacks for the past 5 years, successfully underwent an operation for carcinoma of the breast.

In 1936, Orgain, Wolff, and White reported on the prognosis of paroxysmal auricular fibrillation occurring in otherwise apparently normal hearts. They were able to follow up 40 cases out of a group of 46 . They concluded that the prognosis for life and for the maintenance of adequate cardiac function was, with rare exceptions, excellent. These cases with the addition of numerous private and of 4 hospital cases give a series of 88 cases. The diagnosis of paroxysmal auricular fibrillation and a heart otherwise normal had been made in every one of the 88 cases. The abnormal rhythm had been diagnosed by a physician in 26 cases, by a characteristic history in 10 cases, by physicians on themselves in 3 cases, and in the remaining 49 cases by electrocardiogram. Of these, 78 were traced either in person, by letter, or through their local practitioner.

Of the 78 cases that were traced, 22 were found to have died. The ages of onset and at death of these cases, and comments as to the mode of death, have been listed in the appendix. It will be seen that 6 died with auricular fibrillation complicating toxæmia, operation, or infection; 7 died of cardiac causes, chiefly 
coronary thrombosis; 6 died unexpectedly; and 3 died of causes probably not connected with the heart, most likely of cancer. In none of the 4 cases of coronary thrombosis was there an autopsy. In the 6 who died unexpectedly, one must assume that there was in each case a cardiac cause, most probably coronary thrombosis. There were only 2 who were under the age of 40 at the time of death, and they were both given to alcoholic excess.

The 56 living patients may be divided into groups for the better estimation of the prognosis: 13 of the survivors were physicians and will be considered separately.

(a) Age of onset between 40 and 60, and the time since onset more than two years.-This group contained 23 cases, the average age of onset being 49 years and the average duration since the onset being 12 years. The number of other cases in this age group who had died was 16 , of whom 4 died following operation or infection. Excluding these 4, the average duration from onset to death of the remaining 12 was 13 years, and the average age of onset approximately the same as for the whole group. Of the 23 alive, 6 developed signs of coronary insufficiency, either clinical or electrocardiographic. These developed 16, 15, $10,8,6$, and 4 years after the onset of the paroxysms.

In this group, paroxysmal fibrillation may be the first signs of a serious heart disease, but there does not seem to be any evidence to suggest that the prognosis is any other than that of the underlying heart disease when it becomes evident.

(b) Age of onset below 40, and duration more than two years.-This group contained 16 patients that were living, with an average age at onset of 26 years and duration of 19 years. Excluding one who died of infection and alcoholism, 3 others died after 16,13 , and 8 years, respectively. Only one of those alive appears to have developed cardiac insufficiency, 32 years after the onset, at the age of 70 .

The prognosis in this group appears to be excellent.

(c) Physicians.-This group contained 14 physicians. Only one of these has died. He developed hypertension and permanent auricular fibrillation, eventually dying of carcinoma of the esophagus 24 years after the onset. The average age of onset was 42 years, and the average duration, in 12 of the doctors who had had attacks for more than two years, was 24 years. This high incidence in doctors was noted by Parkinson and Campbell. It suggests that the condition is more common than is usually supposed and that the prognosis is good.

(d) Miscellaneous group.-One man whose attacks came on at the age of 75 was still alive at the age of 86 although his exact condition was not known. In this group there were 3 patients with the abnormal complexes of the type described by Wolff, Parkinson, and White. They were all well after 1, 8, and 18 years, respectively. There were 9 patients who had only one attack. These were still healthy.

To sum up, the occurrence of paroxysmal auricular fibrillation should be regarded in general as having no serious prognostic significance, but when occurring in patients over the age of 40 , it may be the first signs of organic 
heart disease, in which case the prognosis given will depend upon the appearance and severity of the coronary heart symptoms.

Frequency and duration of paroxysms.-As in paroxysmal auricular tachycardia, it is impossible to give any forecast as to either the frequency, the duration, or the prospects of gaining complete freedom from the attacks. In those getting paroxysms with increasing frequency, permanent fibrillation eventually sets in. Occasionally, however, the paroxysms will be frequent for four or five years, causing very great inconvenience and discomfort, and no measure will give any relief until the onset of permanent fibrillation.

In rheumatic heart disease, it is usually thought that paroxysmal fibrillation heralds the approach of permanent fibrillation in the near future. In one patient, however, attacks were frequent for 13 years before this happened. Another had had attacks for 13 years; she was still working, having both mitral and aortic rheumatic disease. Yet another, with a similar heart lesion, had had paroxysmal auricular tachycardia for 10 years, and then for the last 3 years paroxysmal auricular tachycardia and auricular fibrillation. She recognized the difference in rhythm by the difference in the "position of the palpitation" in her chest.

A patient with a probable inter-auricular septal defect had her attacks for the greatest period of time without the occurrence of permanent fibrillation. They started when she was 13 , and when last seen she was 58 ; her activities then were severely curtailed by angina pectoris.

The actual attacks themselves are short. In over half of the total series of 88 cases, they lasted less than 24 hours, and of these the most usual duration was less than 12 hours. Parkinson and Campbell consider that attacks lasting over seven days tend to be permanent, unless treated with quinidine. This is probably true, but with the introduction of quinidine, the outlook is changed. Case 51 had frequent paroxysms of fibrillation, one of which lasted for over three months before he was treated with quinidine. He was well nine years later, with normal rhythm, and was exceedingly active professionally. There were several cases of a similar nature in this survey. With an adequate maintenance dose of quinidine, the prognosis for the continuation of normal rhythm is good.

The prognosis of paroxysmal auricular flutter is essentially that of paroxysmal auricular fibrillation. Orgain, Wolff, and White (1936) recorded 7 cases in patients otherwise normal. It was possible to trace 6 of these who were still alive and well-29, 18, 7, 17, 32, and 9 years, respectively, after the onset. These findings confirm the good prognosis given in the original paper.

\section{SUMmARY AND CONCLUSIONS}

When the cardiovascular system is normal, attacks of paroxysmal tachycardia are uncomfortable, but relatively unimportant incidents.

The probability of any attack ceasing is extremely good, but the occurrence of an attack in a patient seriously ill must be regarded with some apprehension, and the occurrence of heart failure as a result of the attack may lead to the formation of intracardiac thrombi and subsequent emboli. 
The occurrence of paroxysmal auricular tachycardia in apparently healthy persons seems to have no effect upon the prospect of their longevity. When occurring late in life, the prognosis, in general, is that of the underlying heart disease, if present.

Paroxysmal auricular fibrillation is probably common. When occurring in patients below the age of 40 , it may be considered as having no prognostic significance, while in later life the occurrence of fibrillation may, in some cases, be the first sign of serious heart disease.

It is impossible to forecast with any certainty either the frequency or the duration of the attacks of paroxysmal auricular tachycardia and fibrillation.

The basis of this paper formed part of a thesis submitted by one of us (W.T.C.) and accepted for the degree of M.D. of the University of Cambridge. The work was carried out while W.T.C. was holding a Research Fellowship in Medicine, Harvard University, and the Walter Myers Travelling Studentship, Birmingham University, 1938-1939.

\section{REFERENCES}

Bouveret, J. (1889). Rev. Med. Paris, 60, 753, 839.

Bristowe, J. S. (1888). Brain, 10, 164.

Campbell, M., and Elliott, G. A. (1939). Brit. Heart J., 1, 123.

Cowan, J. (1939). Brit. Heart J., 1, 3.

Gallavardin, L., Veil, P., and Froment, R. (1930). J. Med. Lyon., 11, 517.

Hamilton, B. E., and Hurvitz, D. (1932). Amer. Heart J., 7, 274.

Herringham, W. P. (1897). Edin. Med. J., 1, 366.

Hume, W. E. (1930). Lancet, 2, 1055.

Lewis, T. (1936). Diseases of the Heart, London.

Marvin, H. M. (1923). Heart, 10, 279.

Master, A. M., Dack, and Jaffe, H. L.(1937). Ann. intern. Med., 11, 735.

Orgain, E. S., Wolff, L., and White, P. D. (1936). Arch. intern. Med., 57, 493.

Palmer, J. H. (1937). Medical Research Council, Special Series, No. 222.

Parkinson, J., and Campbell, M. (1930). Quart. J. Med., 23, 67.

Sprague, H. B., and White, P. D. (1925). M. Clinics. N. Amer., 8, 1855.

White, P. D., and Bland, E. F. (1932). Amer. Heart J., 7, 1.

Wolff, L., Parkinson, J., and White, P. D. (1930). Amer. Heart J., 5, 685.

\section{APPENDIX}

Deaths that have Occurred in 22 out of 78 Cases with Paroxysmal Auricular Fibrillation and Hearts otherwise Normal.

Sex, Age at Onset, and Age at Death

Comments as to Mode of Death, etc.

\begin{tabular}{|c|c|c|c|}
\hline M. & 53 & 76 & $\begin{array}{l}\text { Apparently enjoyed excellent health until two hours before } \\
\text { death, which was assigned to coronary thrombosis. Had } \\
\text { taken daily quinidine which controlled paroxysms. }\end{array}$ \\
\hline M. & 59 & 71 & $\begin{array}{l}\text { Took quinidine, } 6 \text { grains daily, and had occasional paroxysms. } \\
\text { Died of coronary thrombosis following golf. No previous } \\
\text { symptoms suggestive of coronary insufficiency. }\end{array}$ \\
\hline M. & 54 & 74 & $\begin{array}{l}\text { Angina pectoris one year before death, and much more frequent } \\
\text { attacks of paroxysmal fibrillation. Died suddenly, but no } \\
\text { details available. }\end{array}$ \\
\hline F. & 57 & 66 & $\begin{array}{l}\text { Asthma for thirty years, and died during an attack. Post- } \\
\text { mortem: recent thrombosis in the left ventricle. }\end{array}$ \\
\hline M. & 44 & 62 & $\begin{array}{l}\text { Last three years of life, under treatment for hypertensive } \\
\text { coronary heart disease; rhythm normal all this time. } \\
\text { Autopsy: old coronary thrombosis. }\end{array}$ \\
\hline
\end{tabular}


Sex, Age at Onset, and Age at Death

Comments as to Mode of Death, etc.

\begin{tabular}{|c|c|c|c|}
\hline F. & 49 & 70 & $\begin{array}{l}\text { Died of carcinoma of stomach, attacks of fibrillation having } \\
\text { continued without other cardiac symptoms until death. }\end{array}$ \\
\hline M. & 35 & 59 & $\begin{array}{l}\text { Hypertension and permanent auricular fibrillation for last five } \\
\text { years of life. Died from carcinoma of œsophagus. }\end{array}$ \\
\hline F. & 45 & 65 & $\begin{array}{l}\text { Died after an acute intestinal infection and signs of mental } \\
\text { upset. Her doctor stated: no evidence that heart played any } \\
\text { part in her death. }\end{array}$ \\
\hline F. & 48 & 51 & $\begin{array}{l}\text { Quite well for three years prior to her death. On returning to } \\
\text { work following pneumonia, she dropped dead. }\end{array}$ \\
\hline M. & 52 & 68 & $\begin{array}{l}\text { Free from attacks for the last seven years of his life. Died } \\
\text { unexpectedly, but details not known. }\end{array}$ \\
\hline F. & 64 & 68 & $\begin{array}{l}\text { Died following a convulsive seizure and a number of attacks } \\
\text { of congestive failure. Fibrillation not present at time of } \\
\text { death. }\end{array}$ \\
\hline F. & 29 & 42 & $\begin{array}{l}\text { Died with acute pulmonary œdema following an epileptic } \\
\text { attack. No other details available. }\end{array}$ \\
\hline F. & 44 & 53 & $\begin{array}{l}\text { Died suddenly three years after being passed as having an } \\
\text { irritable normal heart. Permanent fibrillation was thought } \\
\text { to have set in. }\end{array}$ \\
\hline F. & & 5 & Follo \\
\hline M. & 27 & 3. & $\begin{array}{l}\text { Died in congestive failure, with permanent auricular fibrilla- } \\
\text { tion. Alcoholic excesses played a major role. }\end{array}$ \\
\hline F. & 52 & 56 & $\begin{array}{l}\text { Asthma for twenty years. Died during a paroxysm of } \\
\text { auricular fibrillation following a severe septic throat. }\end{array}$ \\
\hline F. & 51 & 51 & $\begin{array}{l}\text { Paroxysm of auricular fibrillation during erysipelas. Normal } \\
\text { rhythm restored with quinidine, but died three months later, } \\
\text { details unknown. }\end{array}$ \\
\hline M. & 53 & 53 & $\begin{array}{l}\text { Right-sided empyema for one year. Developed auricular } \\
\text { fibrillation when this was reopened and died ten days later. } \\
\text { Autopsy showed normal heart. }\end{array}$ \\
\hline F. & 58 & 58 & $\begin{array}{l}\text { Developed paroxysmal auricular fibrillation following an } \\
\text { operation for rectal malignancy. Autopsy showed normal } \\
\text { heart and lungs. }\end{array}$ \\
\hline F. & 66 & 66 & $\begin{array}{l}\text { Developed a severe sore throat a fortnight before death. } \\
\text { Collapsed with onset of auricular fibrillation and died ten } \\
\text { days later. Autopsy showed normal heart. }\end{array}$ \\
\hline F. & 57 & 57 & $\begin{array}{l}\text { Collapsed following an operation. Had auricular fibrillation } \\
\text { for two days and died two days later. Autopsy showed } \\
\text { normal heart. }\end{array}$ \\
\hline M. & 35 & 35 & $\begin{array}{l}\text { Developed auricular fibrillation following exposure a } \\
\text { alcoholic excess. Died of tetanus. }\end{array}$ \\
\hline
\end{tabular}

